Vol. 6 (3), pp. 042-045, June, 2016

ISSN: 2276-7762; ICV: 5.99

Copyright @2016, the copyright of this article is retained by the author(s)

DOI Link: http://doi.org/10.15580/GJBS.2016.3.040916074

http://gjournals.org/GJBS

\title{
Hypolipidaemic and Hypoglycaemic Effects of Aqueous Extracts of Vernoniaamygdalina (Bitter Leaf) on the Blood of Caviaporcellus(Guinea Pig)
}

\section{${ }^{*}$ ZITTE Leelee Famii, ${ }^{1}$ AZUBUINE Justin Chinemerem and ${ }^{2}$ WABALI C. Victor}

${ }^{1}$ Department of Animal and Environmental Biology, Faculty of Science, University of Port Harcourt, P.M.B 5323, Port Harcourt, Nigeria.

${ }^{2}$ Department of Crop/ Soil Science Faculty of Agriculture, University of Port Harcourt P.M.B. 5323 Choba, Port Harcourt, Nigeria.

ARTICLE INFO

Article No.: 040916074

Type: Research

DOI: 10.15580/GJBS.2016.3.040916074

Submitted: 09/04/2016

Accepted: 18/04/2016

Published: 24/06/2016

*Corresponding Author

Zitte Leelee Famii

E-mail: leelee.zitte@uniport.edu.ng, lefzy@yahoo.com

Phone: 08037971401, 08079756415

Keywords:

Vernoniaamygdalina, Caviaporcellus, hypolipidaemic hypoglycaemic
ABSTRACT

This study investigates the effects of aqueous extract of the leaves of Vernoniaamygdalina (Bitter leaves) on blood glucose level and lipid profiles of normoglycaemic and normolipidaemic guinea pigs. The animals whose weights ranged between $350-500 \mathrm{~g}(400 \mathrm{~g})$ were placed in four groups labelled A-D. GroupsA-C respectively received $375 \mathrm{mg} / \mathrm{kg} / \mathrm{day}, 750 \mathrm{mg} / \mathrm{kg} / \mathrm{day}$ and $1125 \mathrm{mg} / \mathrm{kg} /$ day of $\mathrm{V}$. amygdalina aqueous extract for two weeks while group D served as the control. The animals were tested for their glucose level at two days interval, while the lipid profile was estimated after the animals were humanely sacrificed at the end of two weeks treatment. The extract was found to evince significant difference in the treatment over the control at $(P<0.05)$ and a progressive time and dose dependent reduction of blood glucose concentration was observed. Similarly, the extract caused a significant reduction in total cholesterol (TC), low density lipoprotein (LDL) and triglyceride (TG) levels in the treatment groups at $(P<0.05)$. The increase in high density lipoprotein $(H D L)$ was also found to be significant $(P<0.05)$ with respect to the control. This study therefore indicates that Vernoniaamygdalina aqueous extract will be effective in the control of blood glucose and the lipid levels in normoglycaemic and normolipidaemic individuals. 


\section{INTRODUCTION}

Several studies have been carried out on the hypoglycaemic and hypolipidaemicproperties of Vernoniaamygdalina.This paper reports the efficacy of $V$. amygdalina crude aqueous extract on blood glucose level and lipid profile of normoglycaemic and normolipidaemic guinea pigs.

The antithrombotic, hypoglycaemic and hypolipidaemic effects of the leaf extract in diabetichyperlipidaemic and normoglycemic rats have been reported (Adaramoyeet al, 2008). Ethanol extract of the plant is found to reduce body weight by decreasing triglyceride level (Ekpoet al., 2007). Abosi and Raseroka, (2003) and Iwalokun, (2008) also separately reported the Medicinal applications of $\mathrm{V}$ amygdalinato include its use as laxative, antihelminthic and antimalarial.

Osinubi (2005) reports that the aqueous leaf extract produces significant $(\mathrm{P}<0.05)$ reductions in the blood glucose concentrations of normal (normoglycemic) and diabetic (hyperglycaemic) rats 1-12hrs after acute treatment compared with the control.

In a comparative study of the effects of the leaves of Vernoniaamygdalina and Telfairiaoccidentalis, Ugwuet al., (2011) reported a significant effect of the vegetable leaves on the serum cholesterol and triglycerols levels over the control and between each other at $(\mathrm{P}<0.05)$. According to them, $T$. occidentalis diet induces a significantly higher serum HDL concentration compared to $V$. amygdalina diet at the same concentration.

ljehet al.(2008), studied the effects of V. amygdalina aqueous extract on the contraction of the mammary gland and uterus of guinea pig Dams and report a significantly lesser litter-weight in control, than the treatments after five weeks.

Akahet al., (2004) also reportedthat V. amygdalina extract $(80 \mathrm{mg} / \mathrm{kg})$ causes a significant $(P<0.05)$ reduction in blood glucose level in normoglycaemicand alloxan-induced diabetic rats.

Oruambo et al. (2010) opined that unboiledwater extract of $V$. amygdalinaclears the excess blood glucose molecules more rapidly and quantitatively than either the boiled water $V$. amygdalina extract or glucophage, under various conditions.

\section{MATERIALS AND METHODS}

Fresh leaves of Vernoniaamygdalina were obtained from Choba market, Choba, Rivers State, Nigeria. The leaves were washed, sun dried,pulverized and measured into $30 \mathrm{~g}, 60 \mathrm{~g}$ and $90 \mathrm{~g}$. These were respectively macerated in $1 \mathrm{~L}$ of distilled water for 3 days and then stirred and filtered.The residues were further boiled in $400 \mathrm{ml}$ of water for $20 \mathrm{mins}$ and filtered. The process was repeated with $300 \mathrm{ml}$ of water in $10 \mathrm{mins}$. The filtrate of each concentration was mixed togetherstirred thoroughly, then evaporated to one litre volume and stored in a clean coverable container.

Twelve (12) female guinea pigs weighingaveragely $0.4 \mathrm{~kg}$ were obtained from Creek road market, Rivers State. The animals were allowed to acclimate for two weeks at the major's laboratory of the Department of Animal and Environmental Biology, Faculty of Science, University of Port Harcourt.

The animals were grouped into four groups (AD) with three animals per group. Each group was daily administered $5 \mathrm{ml}$ of Vernonia. amygdalina extract orally. Groups A-C were treated with concentrations of 375 , 750 and $1125 \mathrm{mg} / \mathrm{kg} /$ day, while group Dwas daily administered $5 \mathrm{mls}$ of distilled water orally. The treatment was for a period of 2 weeks, during which, Blood glucose level was monitored at two days interval with the aid of aglucometer (a glucose testing kit).

At the end of the two weeks, the animals were fasted over-night, anaesthetised under chloroform and sacrificed. Then the blood was collected in a lithium heparin bottle for lipid profile and Blood glucose analysis. The total cholesterol (TC) was determined by the enzymatic end-point method using Cholesterol Oxidase - Peroxidase (CHOD-PAP) reagent for hydrolysis and oxidation. Triglycerides were determined after enzymatic hydrolysis with lipases by the Glycerol-3phosphate Oxidase- Peroxidase (GPO-PAP) method.

Low density lipoprotein (LDL), very low density lipoproteins (VLDL) and chylomicron fractions were precipitated quantitatively by the addition of phosphotungstic acid in the presence of magnesium ions. After centrifugation, the cholesterol fraction, which remained in the supernatant, was determined.

Low density Lipoprotein concentration in the blood was calculated thus,

HDL).

$$
\mathrm{LDL}=\text { Total Cholesterol }-(\text { Triacylglycerol } \div 2.2+
$$

Values were presented as mean \pm standard deviation (S.D). One way ANOVA was used to analyze the data at $\mathrm{P}=0.05$.

\section{RESULTS AND DISCUSSION}

Blood sugar was reduced in group $A$ and $B$ from initial values of $5.40 \pm 0.60$ to $4.60 \pm 0.17$ and $5.43 \pm 0.59$ to $4.10 \pm 0.10$ in two weeks, i.e. a $14.81 \%$ and $24.49 \%$ reduction respectively, while that in group $\mathrm{C}$ was reduced from $5.47 \pm 0.25$ to $3.73 \pm 0.22 \mathrm{mmol} / \mathrm{L}$ i.e. a $31.81 \%$ reduction. However, the control had a normal rise and fall of blood glucose levels with an initial value of $4.67 \pm 0.35$, and rose to a peak of $4.80 \pm 0.10$ on the $9^{\text {th }}$ day and fell to $4.70 \pm 0.27$ on the final day. With an increase of $0.64 \%$ (fig 1) $V$. amydalina aqueous extract was observed to cause a significant $(P<0.05)$ reduction in blood glucose level ofnormoglycaemicGuinea pig in all 
treatment groups as against the control which was not significantly $(P>0.05)$ different from the initial value.

Regarding the effect of $V$. amygdalina aqueous extract on the lipid profile of guinea pigs, the extract evinced a significant difference $(P<0.05)$ with respect to the control in the parameters of lipid profile, causing the highest change in the group fed with the highest $V$. amygdalina concentration (fig2).

The results from this study reveal significant reduction in the blood glucose concentrations of normoglycaemic guinea pigs treated with various concentrations of Vernoniaamygdalina aqueous extract. The findings of this investigation therefore, suggest that the plant extract could stimulate insulin production and glucose utilization to cause anti-hyperglycaemic effect on the mammalian experimental model.

This result agrees with the findings of Akahet al., (2004) who report that $V$. amygdalina extract $(80 \mathrm{mg} / \mathrm{kg})$ causes a significant $(\mathrm{P}<0.05)$ reduction in blood glucose level in normoglycemic and alloxan-induced diabetic rats. It also has similarities with the results of Oruambo et al. (2010) who opined that unboiled water extract of $V$. amygdalinaclears the excess blood glucose molecules more rapidly and quantitatively than either the boiled water $V$. amygdalina extract or glucophage, under various conditions.

The results of lipids assayed in this study show that there was a significant difference $(P<0.05)$ in $T C$, TG LDL and HDL in the experimental groups as compared to the control. Therefore, the administration of aqueous extract of Vernoniaamygdalina to normolipidaemic guinea pigs decreases plasma TC, TG and LDL, and increases the HDL levels. There was a dose response decrease in the levels of TC, TG, and LDL, with respect to increasing aqueous extract concentration. Thus the $1125 \mathrm{mg} / \mathrm{kg} /$ day extract evinced the highest reduction in the three parameters, while HDL levels was shown to be high in treatment with the highest concentration of extract The results showed that the extract significantly lowered the serum LDL concentrations relative to the control. A similar result was also reported by Ugwu et al, (2011) who said that there was a significant effect of $V$. amygdalina leaves on the serum cholesterol and triglycerols levels, over the control and between each treatment at $(\mathrm{P}<0.05)$.

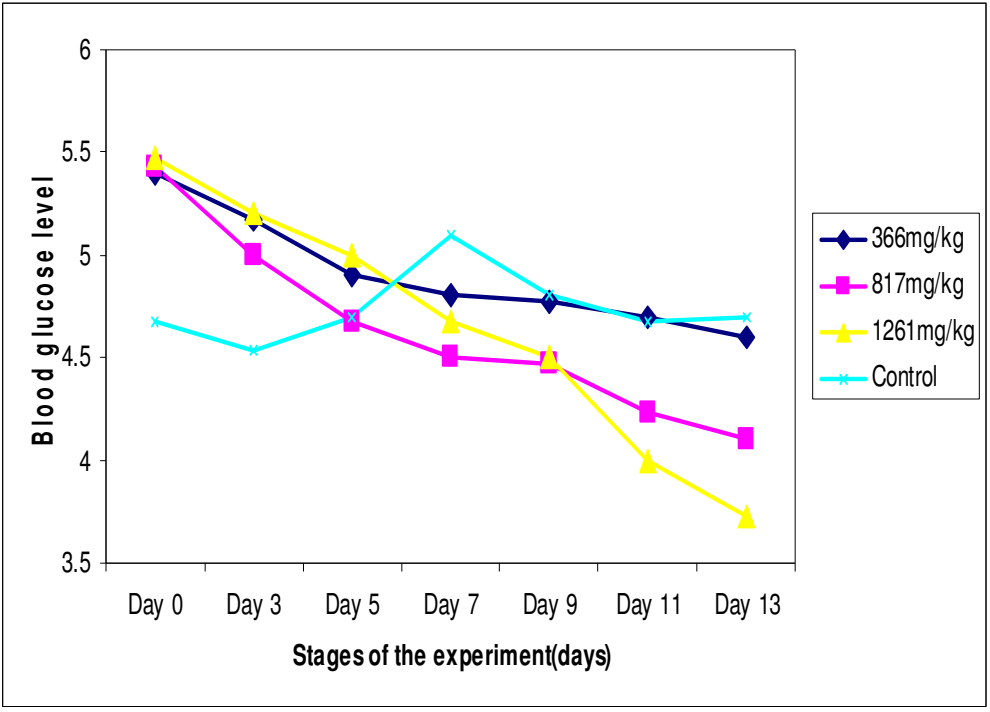

Fig. 1: Changes in the blood glucose level of the treated and control groups at the different stages of experiment 


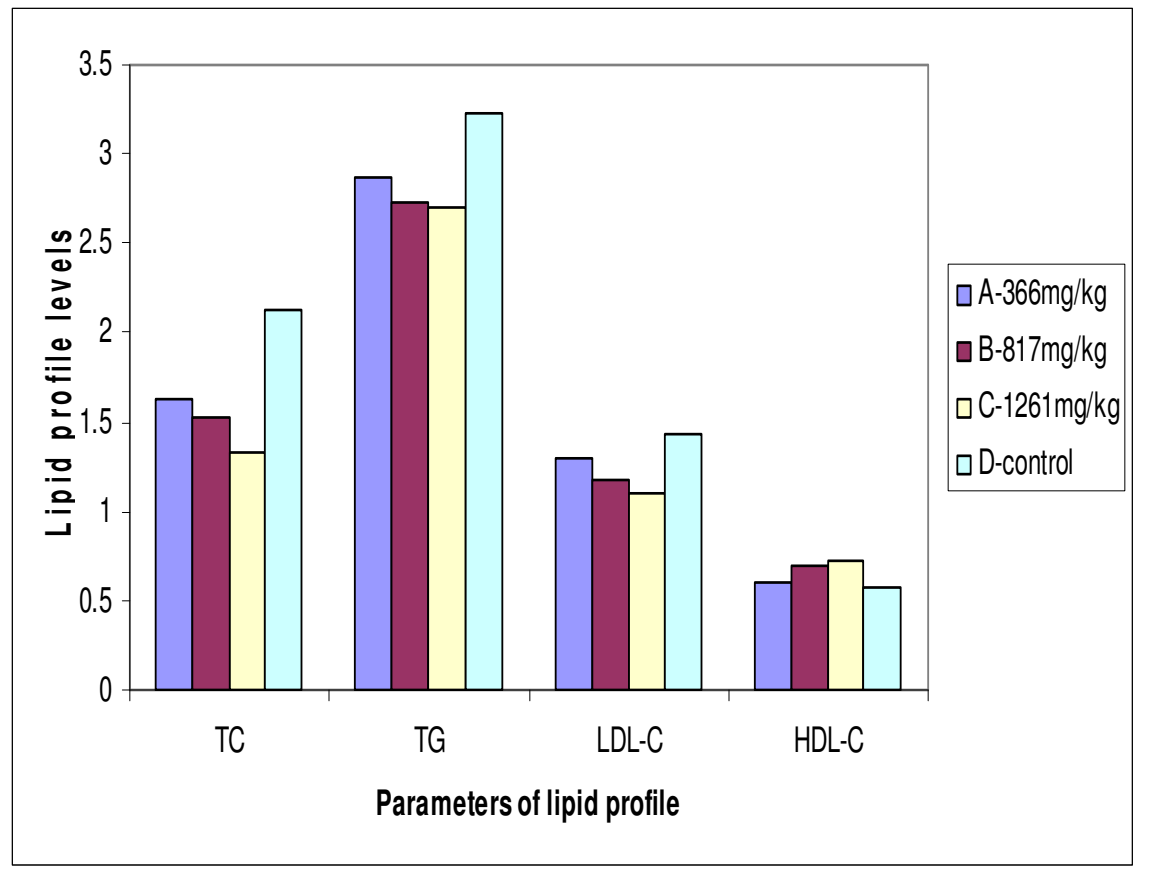

Fig. 2: Changes in the lipid profile of the experimental and control groups

\section{CONCLUSION}

The results from the study showed that $V$. amygdalina aqueous extract is effective in the control and reduction of blood glucose and greatly influence the lipids profile of normoglycaemic and normolipidaemicalbino rats and by extrapolation, it will be a good therapeutic agent against these two life-threatening pathological conditions in man.

\section{REFERENCES}

Abosi, A. O. and Raseroka, B. H. (2003).In vivo antimalarial activity of Vernoniaamygdalina.Br. J. Biomedical Sci. 60: 89 -91.

Adaramoye O., Akintayo O., Achem J. and Fafunsoo M. A. (2008). Lipid lowering effects of methanolic extract of Vernoniaamygdalinaleaves in rats fed on high cholesterol diet. Vascular Health and Risk Management, 4:235-241.

Akah P. A., Njoku O., Nwanguma A. and Akunyili D. (2004). Effects of aqueous leaf extract of Vernoniaamygdalinaon blood glucose and triglyceride levels of Alloxan-induced Diabetic rats (Rattusrattus). Animal Res. Int. 1(2):90-94.

Ekpo A., Eseyin O. A., Ikpeme A. O. and Edoho E. J. (2007).Studies on some biochemical effects of
Vernoniaamygdalina in rats.As. J. Biochem.,2: 193197.

Ijeh I. I., Igwe K. K. and Ejike E. C. (2008). Effects of leaf aqueous extracts of Vernoniaamygdalina Del on contraction of mammary gland and uterus of Guinea pigs Dams.Ame.Journ.OfTrop. Med. \&Pub. Health. 1(3): 107-116.

Iwalokun, B. A. (2008). Enhanced antimalarial effects of chloroquine by aqueous Vernoniaamygdalina leaf extract in mice infected with chloroquine resistant and sensitive Plasodiumbergheistrains. African Health Sciences 8: 25-35.

Oruambo I. F., Onuba E. O. and Anyim S. D. (2010). Glucose tolerance test in hyperglycemic Guinea pigs treated with aqueous Vernoniaamygdalina.Medical Journ.oflsl. World Acad. ofSci.18:1, 21-26.

Osinubi A. A. (2005). Effects of Vernoniaamygdalinaand Chlorpropamide on blood glucose. Med. Journ. Of Isl. World Acad.Of Sci. 3, 115-119.

Toth, Peter (2005). "The "Good Cholesterol" HighDensity Lipoprotein" Circulation111 (5): e89-e91. Retrieved 2 June 2011.

Ugwu C. E., Olajide J. E., Alumana E. O. and Ezeanyika L. U. (2011). Comparative effects of the leaves of Vernoniaamygdalina and Telfairiaoccidentalis incorporated diets on the lipid profile of rats.Afri.Journ.Of Biochem. Res.5(1), Pp. 28-32. 